\title{
Fundamental study on relationship between human injury probability due to fall and the fall height
}

\author{
Yasumichi $\mathrm{HINO}^{\mathrm{a},{ }^{*}}$ \\ ${ }^{a}$ Construction Safety Research Group, National Institute of Occupational Safety and Health JAPAN, 1-4-6, \\ Umezono, Kiyose, Tokyo, JAPAN
}

\begin{abstract}
Many fatal accidents due to falling from height have happen at construction sites in Japan. The purpose of this study is about to seek new prevention methods of fatal accidents due to falling. For the first step, this study was carried out to find out "cause of death" in labor accidents by using past statistics data and was analyzed it. For the second, Butt dropping tests were carried out to measure impact load and acceleration of human head and neck by using simplified human model. After that, relationship between the human injury probability and the fall height was discussed by comparing with experimental results and some impact tolerance values for human. From the results of this study, impact force might be able to head trauma involved not only skull fracture but also cervical spinal cord injury. These results suggest needs to explore new protection equipment for head and cervical injuries prevention.
\end{abstract}

Keywords: Labor accident, falling accident, head and neck injury, impact force and acceleration

\section{Introduction}

In Japan, labor accidents due to falling from heights occur frequently every year. In this study we explore an ideal scenario of preventive measure. In the resent falling accidents, the main injury region of victims was human head, according to the past statistics data on labor accident. These were presented in the annual reports published by Japan's ministry of labor [4]. Figure 1 shows the number of fatal accidents categorized into main injury region of victims. In particular, the head injury accounts for about $70 \%$ of fatal accidents due to falling. The risk of death due to brain contusion or brain hemorrhage is high when the head is subjected to serious impact.

However, forensic autopsy has rarely been carried out in Japan. Thus, main injury region observed outside of the victims may not have directly relevance to the victim's death. For example, there are also some possibilities of death from suffocation or physical impediments due to cervical injury. It is because a lot

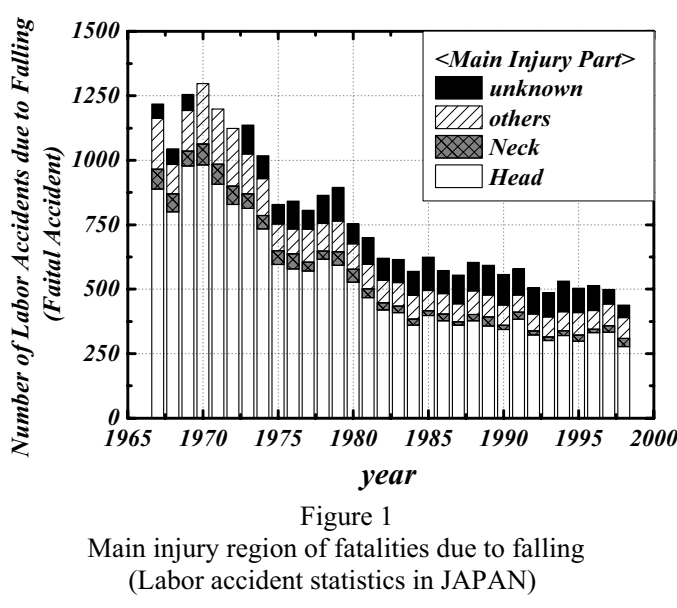

of very important organ such as airways, main artery, and some nerve fibers are inside the cervical region. Nerve fibers for controlling diaphragm are also inside the joint part between bottom of human skull and

\footnotetext{
Y Yasumichi HINO. E-mail: hino@s.jniosh.go.jp
} 
topside cervical vertebra. Table 1 shows an analytical result investigated by forensics experts on cause of victim's death in an emergency hospital in JAPAN [7]. In this analysis, patients was divided into two groups, and about $50 \%$ of patients, who died after they arrived at hospital, died mainly due to head part injury. However, Most of patients, who died before they arrived at hospital, died due to have cervical injuries.

Hence, it is necessary to prevent direct impact to the head in order to reduce fatal accidents due to falling.

Countermeasures to prevent falling accidents have been carried out at accident black spots, such as high places in construction sites. The main method has been the setting up of temporary facilities, such as scaffolds or guardrails. These facilities can reduce the chance of falling and also can act indirectly to avoid direct impact to the head. However, safety and security at each workplace strongly depends on the skill of the business proprietor because the assembly methods of such facilities vary at each workplace. Since it is extremely difficult to improve the skills of all owners, it is also difficult to eliminate unsafe workplaces. Therefore, direct countermeasures as well as indirect countermeasures are necessary to achieve labor protection without requiring any skills from employers. This kind of idea can be seen in the automobile crash safety field. They includes all aspects not just measures for reducing the likelihood of crashing. A wide variety of countermeasures have been implemented for the protection of passengers and pedestrians in this field.

In this study, the ideal capacity of human protective equipment was investigated through carrying out drop tests using a simplified human model. Experiments were set out to determine impact forces and accelerations of human head model due to falling from height to virtual ground surface.

\section{Experimental Method}

Vertical drop tests were carried out in this experiment using a simplified human model constructed with head, neck and body. Photo 1 shows the basic model. The head part was ISO head adult model which has been used as a pedestrian head in automobile crash tests $[1,8]$. The neck model developed in this study can reproduces the axial direction characteristics of the human neck. By consulting literature [5], the neck model characteristics were modeled into a serial spring which could express bi-linear type
Table 1

An analytical result investigated by forensics experts on cause of victim's death in an emergency hospital in JAPAN

\begin{tabular}{|l|c|c|}
\hline & $\begin{array}{c}\text { Patients who died after } \\
\text { they arrived at hospital }\end{array}$ & $\begin{array}{c}\text { Patients who died before } \\
\text { they arrived at hospital }\end{array}$ \\
\hline Total Patients & 105 & $\begin{array}{c}40 \\
\text { They all have head injury })\end{array}$ \\
\hline Head injury & $54 / 105(51.4 \%)$ & - \\
\hline Cervical injury & $4 / 105(3.8 \%)$ & - \\
\hline Head and Cervical injury & $31 / 105(29.5 \%)$ & $32 / 40(80.0 \%)$ \\
\hline Other region injury & $16 / 105(15.2 \%)$ & - \\
\hline
\end{tabular}

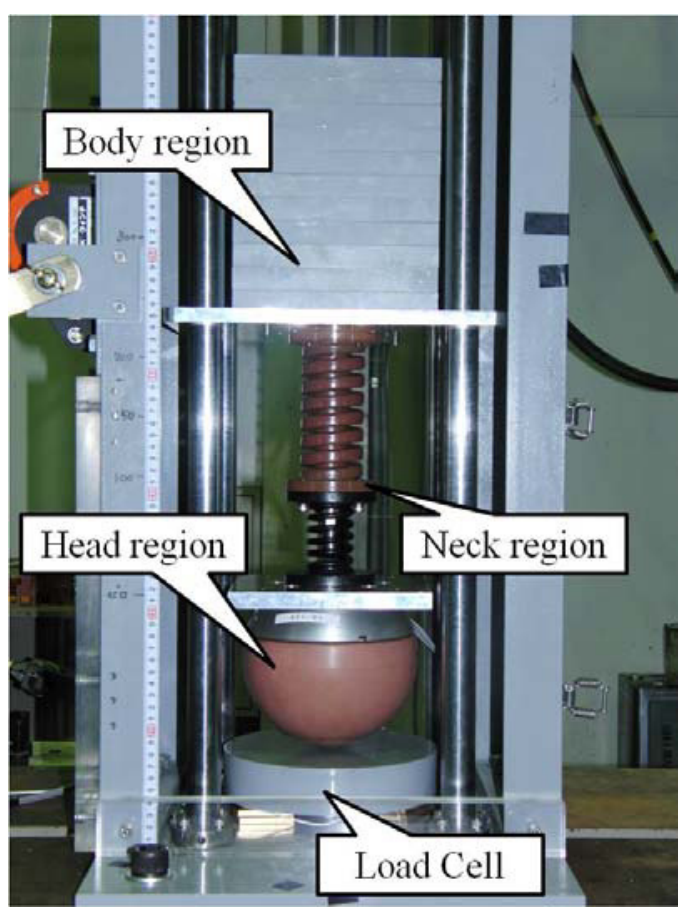

Photo 1

Experimental Model (Basic Model)

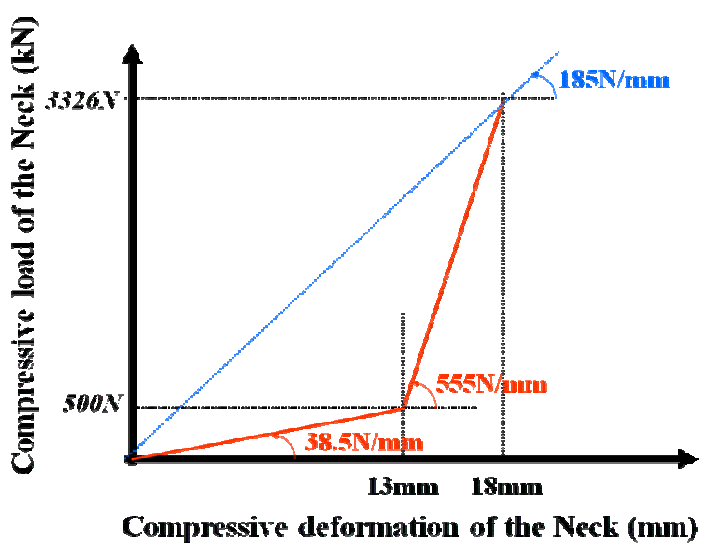

Figure 2

Characteristics of the human neck model in this study 
force-displacement relation in the axial direction (see Figure 2). The body part represents the weight of the torso minus the head and neck. The model combined with head, neck and body was used as a basic model in this study. Total human weight of the basic model was set to $65 \mathrm{~kg}$ which is the Japanese male's average weight [6]. We tested not only the basic model shown in Photo 1 but also the head model shown in Photo 2 was tested independently and the resulting experimental data were compared. Head acceleration at the center of gravity was measured with 3dimensional accelerometer manufactured by KYOWA ELECTRONIC INSTRUMENTS (model number: ASE-A-500SA5). Impact forces acting on the human head region were also measured with a piezotype load cell manufactured by PCB PIEZOTRONICS (model number: Model200C50). Experimental data was sampled with $10000 \mathrm{~Hz}$ and was filtered by class 1000 characteristics defined by ISO6487 [2].

\section{Experimental Results}

Table 2 shows drop test results by using the head model and the basic model. "Height" in Table 2 means the vertical minimum distance between impact plate and initial location of the human head model surface. "HIC" values in Table 1 are the results calculated with the equation (1) defined by literature [3].

$$
\text { HIC }=\left[\frac{1}{t_{2}-t_{1}} \times \int_{t_{1}}^{t_{2}} \frac{a(t)}{9.8} \times d t\right]^{2.5} \times\left(t_{2}-t_{1}\right)
$$

where $a(t)$ : head acceleration at the center of gravity $\left(\mathrm{m} / \mathrm{sec}^{2}\right)$

$$
\mathrm{t} \text { : time (sec) }
$$

The "head acc." shows 3-dimensional maximum head acceleration. This table clearly shows that the values of head accelerations and of the impact forces depend on the "Height". Also, HIC values of these different models were mostly equal in case their

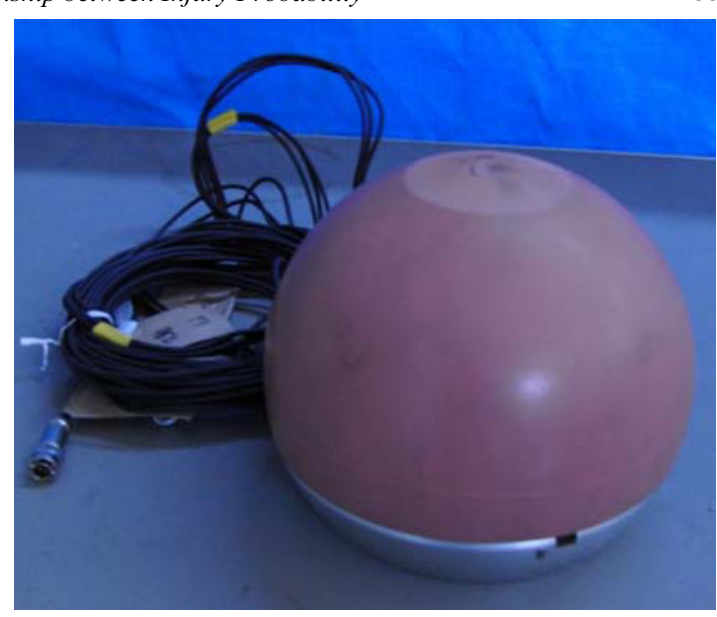

Photo 2

Experimental Model (Head Model)

models fell from the same height. Against that, the tendency of the impact force was different. Maximum impact forces of these basic model results were larger than these of head model results in the same "Height".

Figure 2 shows time histories of the head acceleration and impact force when each model fell from $300 \mathrm{~mm}$ to the impact plate. Maximum impact force of the head model occurred at point $\mathrm{A}$ in the figure and after $5 \mathrm{msec}$, the acceleration became very small. The impact force of the basic model at point $A$ in the figure also occurred at the same time. Head acceleration time history of the basic model is the same as the head model from $0 \mathrm{msec}$ to $5 \mathrm{msec}$. However, the impact values at point $\mathrm{A}$ are different from each other. Occurrence time of the maximum head acceleration and impact force were also different. The maximum impact force of the basic model occurred at point $\mathrm{C}$. But that of the head model occurred at point A. To examine this difference, high-speed camera data was used. From display analyses, they became clear that point $\mathrm{A}$ is the time when the head just impacted to

Table 2

Drop test results by using the head model and the basic model

\begin{tabular}{l|c|c|c|c|c}
\hline \multirow{2}{*}{ Model } & $\begin{array}{c}\text { total mass } \\
(\mathrm{kg})\end{array}$ & $\begin{array}{c}\text { height } \\
(\mathrm{mm})\end{array}$ & $\begin{array}{c}\text { head acc. } \\
(\mathrm{G})\end{array}$ & HIC & $\begin{array}{c}\text { Road Cell } \\
(\mathrm{kN})\end{array}$ \\
\hline \hline \multirow{3}{*}{ head model } & 4.5 & 100 & 84.3 & 91 & 3.5 \\
\cline { 2 - 6 } & 4.5 & 200 & 146.8 & 283 & 7.1 \\
\cline { 2 - 6 } basic model & 4.5 & 300 & 203.6 & 552 & 10.3 \\
\cline { 2 - 6 } & 65 & 100 & 173.5 & 96 & 9.9 \\
\hline
\end{tabular}

the impact plate and the point $\mathrm{B}$ is the exact time 


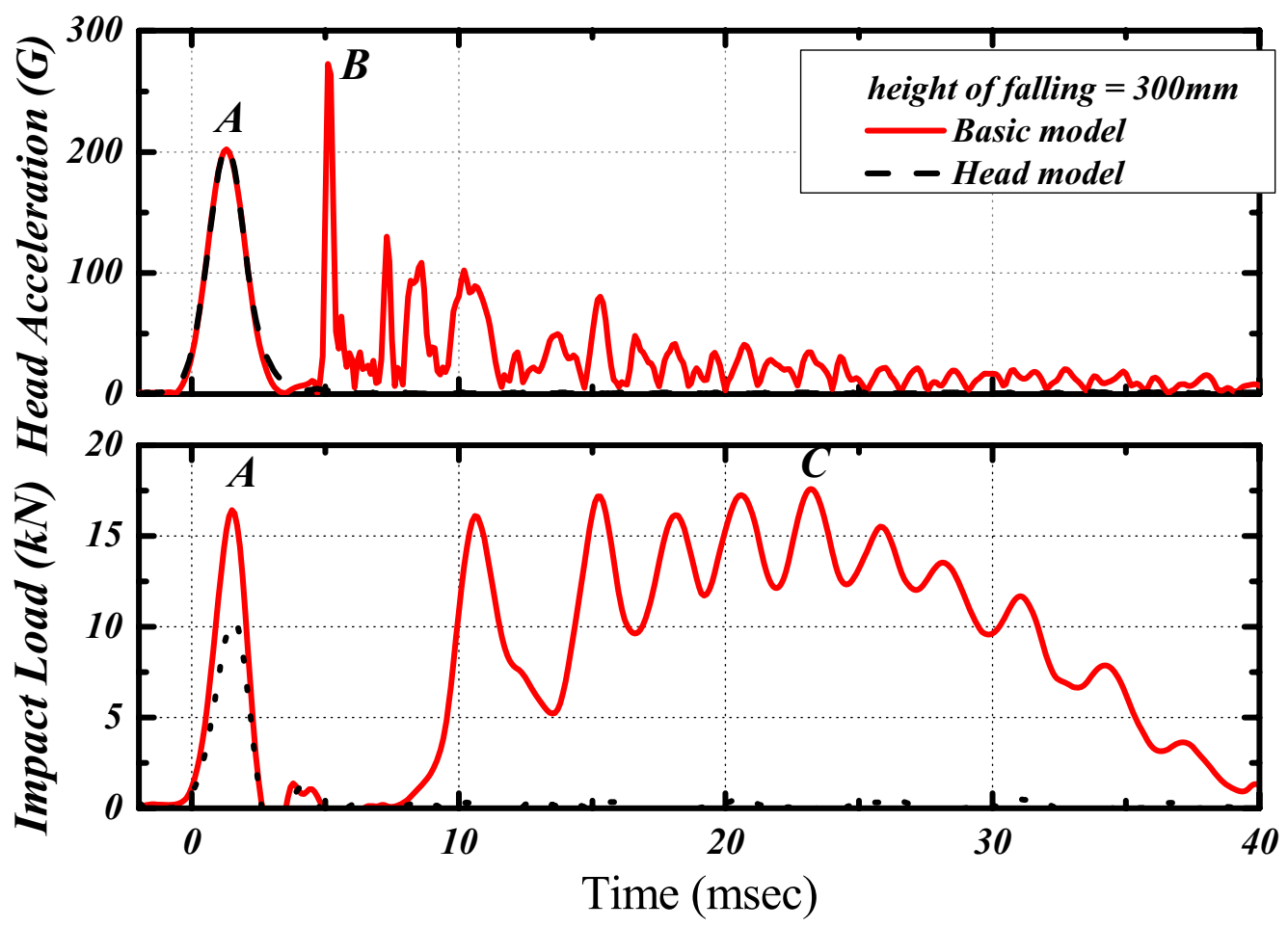

Figure 3

Time histories of the impact acceleration and impact load of the head model

(Drop height of these experiments is in case just $300 \mathrm{~mm}$ )

when the rebounded head impacted on the body part in the air, and that point $\mathrm{C}$ is the exact time when the unified head and other body parts impacted on the plate.

\section{Summary}

It was ascertained by some experiments in this study that the HIC value of the basic model could obtain the same value regardless of human body weight. It can be said that the heights of falling in this experiment were not high, but over $10 \mathrm{kN}$ of impact forces were observed. This value is enough to cause a cervical vertebrae fracture. As stated earlier, head injuries are the major cause of fall fatalities in the construction industry. Compared with other industries, deaths from head injury and spinal-cordinjury are very prevalent in the construction industry. This result suggests the need to explore a new form of protection for the head and cervical region.

\section{References}

[1] ISO145133. Road Vehicle-Pedestrian Protection-Head Impact Test Methods, 2006.

[2] ISO6487 Road vehicles - Measurement techniques in impact tests - Instrumentation, Fourth edition, 2002

[3] Ministry of Transport JAPAN, Traffic Safety and Nuisance Research Institute's Automotive Type Approval Test Standards, Koubunsha, 1998. (in Japanese)

[4] Ministry of labor JAPAN, Labor Standards Bureau. 1967 1999. (in Japanese)

[5] Narayan Yoganandan, et al, Dynamic Characteristics of the Human Cervical Spine, STAPP, 1995, pp195-202.

[6] Research Institute of Human Engineering for Quality Life, Japanese body size dat, 1997. (in Japanese)

[7] Sekio Tominaga, et al, Countermeasure for spinal cord injury, Medical journal of Shimane prefectural central hospital, Vol.19 No.1, 1991, pp8-14. (in Japanese)

[8] Yasuhiro Matsui, Masaaki Tanabashi, Development of Pedestrian Headform Impactor in Compliance with ISO and Japanese Technical Standards. $19^{\text {th }}$ Bioengineering Lecture Meeting, 2007, pp462-463. Japan society of mechanics engineers. (in Japanese) 